\title{
Precise moisture monitoring for various soil types using handheld microwave-sensor meter
}

\begin{abstract}
A handheld microwave reflectometer-sensor system is developed to operate from 1.35 to 1.95 $\mathrm{GHz}$ and used to measure volumetric and gravimetric moisture content in various types of soils from $0 \%$ to $45 \%$. A small monopole driver from coaxial line is buried into the soil, and its reflected voltage is measured and correlated with corresponding soil moisture content obtained from oven dying method. The measured reflected voltage is dependent on the nonlinear change of dielectric properties of the soil with the moisture content.
\end{abstract}

Keyword: Frequency domain reflectometry; Monopole sensor; Reflected voltage; Relative permittivity of soil; RF handheld reflectometer; Soil moisture 